\title{
Immunohistochemical Localization of Low Density Lipoprotein Receptors in Adrenal Gland, Liver, and Intestine
}

\author{
Loren G. Fong, ${ }^{*}$ Elizabeth Bonney, ${ }^{\ddagger}$ Jon C. Kosek, ${ }^{\$}$ and Allen D. Cooper ${ }^{\star \ddagger}$ \\ ${ }^{*}$ Research Institute, Palo Alto Medical Foundation, Palo Alto, California $94301 ;{ }^{\ddagger}$ Department of Medicine, Stanford University Medical \\ School, Stanford, California 94305; and ${ }^{\S}$ Department of Pathology, Palo Alto Veterans Administration Hospital, Palo Alto, \\ California 94305
}

\begin{abstract}
The localization of LDL receptors in adrenal gland, liver, and intestine was studied using immunohistochemistry. The antiLDL receptor antibody used was shown to be monospecific and did not react with striated muscle, a tissue which has a very low level of LDL receptors. Similarly, cerebral cortex showed only faint reactivity and that was to an area previously demonstrated to have LDL receptors. Adrenal gland was intensely reactive with the zona fasciculata, having a greater density of receptors than the zona reticularis. In normal liver, LDL receptors were present on the sinusoidal membranes and were sparse in the areas of hepatocyte-to-hepatocyte contact without an obvious portal to central gradient. LDL receptors were present throughout the intestine. In jejunum, staining was most intense at the base of the villus and extended up toward the villus tip. At the base of the villus, the receptor was primarily at the basal lateral membrane, but toward the villus tip, there was appreciable intracellular staining. Staining in crypts was more faint; in duodenum, staining in crypts equaled that in the villus region in intensity. In colon, there was intense staining throughout the epithelial cells.

These results provide new information about the cellular and subcellular localization of LDL receptors and raise the interesting possibility that there is a role for LDL-derived cholesterol in new lipoprotein formation.
\end{abstract}

\section{Introduction}

The LDL receptor plays a central role in cholesterol homeostasis (1). Between $50 \%$ and $70 \%$ of the body's LDL receptors are located in the liver $(2,3)$, and changes in the concentration of LDL receptors in this organ induce changes in the serum cholesterol level (4). The adrenal gland (5) and other steroidogenic organs (6) have the greatest density of LDL receptors, and, although their level may vary as a function of steroidogenic activity, because of the small size of the organs, they may not

A preliminary report of a portion of this work was presented in February 1986 at the Western Regional meeting of the American Federation for Clinical Research in Carmel, CA, and published in abstract form (1986. Clin. Res. 34:27a).

Dr. Bonney's present address is Department of Obstetrics and Gynecology, Brigham and Women's Hospital, Boston, MA 02114.

Address reprint requests to Dr. Cooper, Research Institute, Palo Alto Medical Foundation, 860 Bryant Street, Palo Alto, CA 94301.

Received for publication 6 February 1989 and in revised form 21 April 1989.

J. Clin. Invest.

(C) The American Society for Clinical Investigation, Inc. $0021-9738 / 89 / 09 / 0847 / 10 \quad \$ 2.00$

Volume 84, September 1989, 847-856 affect the serum LDL level. No other organ appears to have a high density or large mass of receptors, but most organs express receptors or can be induced to express them in vivo by inducing hypocholesterolemia (7), and virtually all normal tissues studied can express LDL receptors during tissue culture under lipid-deprived conditions. Thus, these receptors and their expression appear to play an important role in the normal functioning of many cell types as well as in regulating serum LDL levels.

In this regard, the intestine is a particularly interesting organ. It is a major site of cholesterol and lipoprotein synthesis. In addition, studies of LDL removal consistently suggest that $\sim 10 \%$ of LDL receptor-mediated LDL removal occurs in this organ $(2,3)$. Further, the intestine has been implicated as a site of HDL removal $(8,9)$, particularly after the induction of hypocholesterolemia (7). Both LDL receptor- (10) and nonLDL receptor- (9) mediated uptake have been implicated in this process. It has also been suggested that the LDL receptors are localized to the crypt cells and distributed equally between jejunum and ileum (10). Earlier work from our laboratory (11) failed to find any LDL-mediated regulation of cholesterol synthesis in short-term organ explants from canine intestine. However, rabbit intestinal explants, maintained in culture for a longer period, were responsive to LDL (12). Further, Gebhard and Prigge (13) found LDL responsiveness in segments of dog intestine that had been excluded from the alimentary stream before biopsy. Others have found LDL receptor mRNA in the intestine (14).

Thus, LDL receptors are almost certainly present in this organ and could potentially play several roles in cholesterol homeostasis. Crypt cells turn over rapidly (15), and LDL-derived cholesterol, along with newly synthesized cholesterol, could fulfill the need for the sterol in membrane synthesis. On the other hand, lipoprotein production also requires a substantial cholesterol supply which may be only partially met by dietary and biliary sources. In fact, despite an early report to the contrary (16), villus cells are an active site of cholesterol synthesis $(17,18)$.

Studies of ligand binding in the intestine have not provided clear-cut results. Suzuki et al. (9) have found some LDL receptors, but noted a high nonspecific component. They have suggested that HDL is the principal lipoprotein that binds to intestine (9). In unpublished studies, we were able to demonstrate specific LDL binding, but were troubled by the high level of background binding in this organ (Fields, F. J., and A. D. Cooper, unpublished observation).

Because studies with intact organs may fail to reveal the contribution of quantitatively minor, but physiologically important cell types, and cell isolation necessarily disrupts the membrane organization, in situ techniques often provide new insights. Accordingly, we have used immunohistochemistry to localize the distribution of LDL receptors in the intestine and 

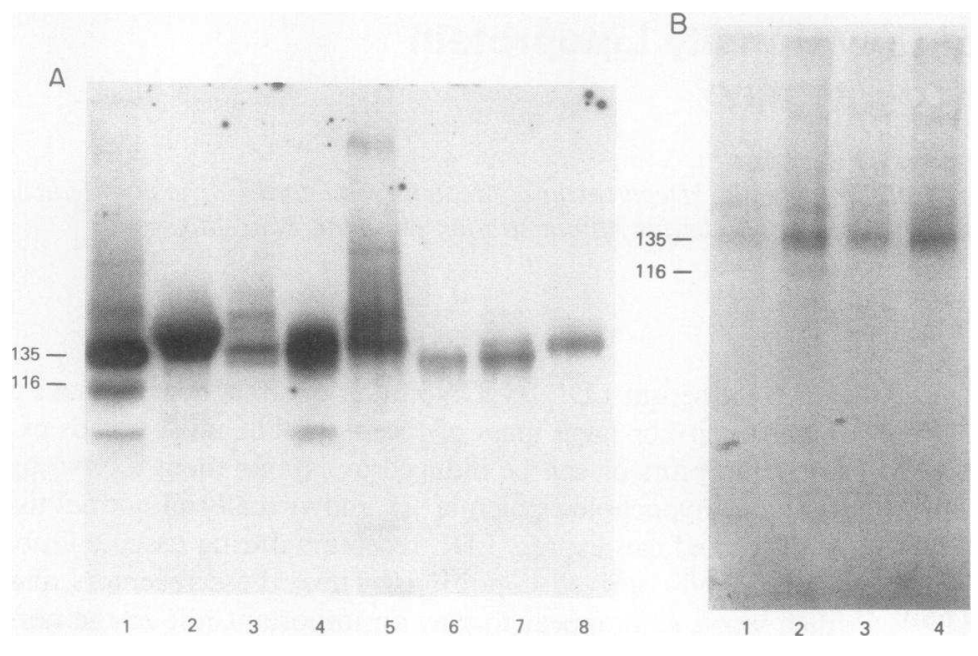

Figure 1. Immunoblots of membrane proteins in various tissues. Membranes were prepared by ultracentrifugation of homogenates of various tissues. The membranes $(300 \mu \mathrm{g}$ of protein) were solubilized in CHAPS and subject to electrophoresis on 3-8\% polyacrylamide gels. Protein was transferred to nitrocellulose, and the nitrocellulose strips were incubated, first with polyclonal rabbit anti-LDL receptor antiserum and then with ${ }^{125} \mathrm{I}$-goat anti-rabbit IgG. The location of the immunoreactive protein was visualized by radioautography. $(A)$ Lane 1 , liver from ethinyl estradiol-treated rats, only $30 \mu \mathrm{g}$ protein was used in this lane; lane 2 , liver; lane 3 , adrenal; lane 4, whole intestine; lane 5 , villus; lane 6 , cerebral cortex; lane 7, cerebellum; lane 8 , skeletal muscle. $(B)$ Membranes were prepared as described in $A$, except that the membranes (lanes 1 and 3, $150 \mu \mathrm{g}$; lanes 2 and 4, $300 \mu \mathrm{g}$ ) were separated on a $5 \%$ polyacrylamide gel. Lanes 1 and 2 , villus; lanes 3 and 4 , crypt.

have found that they are present, not only in crypt cells as expected, but are also abundant in the mid-villus region.

\section{Methods}

Materials. Ammonium acetate, paraformaldehyde, and hydrogen peroxide were purchased from J. T. Baker Chemical Co. (Phillipsburg, NJ). (3-[3-Cholamido-propyl]-dimethylammonio)-1-propanesulfonate (CHAPS), ' 3,3'-diaminobenzidine, and nickel chloride were purchased from Sigma Chemical Co. (St. Louis, MO). Nonfat dry milk was purchased from Carnation. Triton X-100 was supplied by Calbiochem-Behring Corp. (La Jolla, CA). Normal goat serum and minimum essential medium (MEM) were obtained from Gibco Laboratories (Grand Island, NY). Goat anti-rabbit IgG horseradish peroxidase (HRP)-coupled $\mathrm{F}\left(\mathrm{ab}^{\prime}\right)_{2}$ fragment was purchased from Zymed Laboratories (S. San Francisco, CA). OCT embedding medium was obtained from Miles Scientific Div. (Naperville, IL) and Permount from Fisher Scientific Co. (Fair Lawn, NJ).

Animals. Adult male Sprague-Dawley rats weighing between 200 and $300 \mathrm{~g}$ were fed Purina rat chow and maintained in a light-cycled environment. They were fasted overnight in metabolic cages and then killed by decapitation.

Preparation of frozen tissue sections. Sections of liver, adrenal, skeletal muscle, duodenum, jejunum, and ileum were immediately exised and placed in ice-cold Hanks' buffered saline solution without added calcium or magnesium, with $1 \mathrm{mM}$ phenylmethylsulfonyl fluoride and $1 \mathrm{mM}$ EDTA for protease inhibition. The tissues were then placed in OCT embedding compound (Miles Scientific Div.) and frozen over dry ice. Using a cryostat (Minotome, International Equipment Co., Needham, MA), $6 \mu \mathrm{m}$ thick sections were placed on slides previously dipped in a solution of $0.1 \%$ gelatin and $0.01 \%$ chromium potassium sulfate $\left[\mathrm{CrK}\left(\mathrm{SO}_{4}\right) 12 \mathrm{H}_{2} \mathrm{O}\right.$ ] by weight in distilled $\mathrm{H}_{2} \mathrm{O}$ and allowed to air dry. Sections were allowed to air dry onto the slides.

Monoclonal antibody staining technique. Slides were incubated with monoclonal anti-receptor antibody (P1B3) or control antibody $150 \mu \mathrm{g} / \mathrm{ml}(50 \mu \mathrm{l}$ per section) for $15 \mathrm{~min}$. Slides were then rinsed and soaked in cold PBS for $5 \mathrm{~min}$. Slides were next incubated with horseradish peroxidase-conjugated, affinity-purified rat anti-mouse IgG (Jackson Immunoresearch, Westgrove, PA) or horseradish peroxidase-conjugated goat anti-rabbit IgG (Tago, Inc., Burlingame, CA). The dilution of second antibody was determined for each batch ( $1: 5$ for rat anti-mouse). Slides were again rinsed and soaked in PBS. Finally, peroxidase activity was visualized using a solution of diaminobenzi-

1. Abbreviations used in this paper: CHAPS, (3-[3-cholamidopropyl]dimethyl-ammonio)-1-propanesulfonate; HMG, 3-hydroxy-3-methyl glutaryl; LRP, LDL receptor homologous protein. dine $(25 \mathrm{mg} / \mathrm{ml}$ in 2-methoxy ethanol) mixed with PBS and $0.03 \%$ $\mathrm{H}_{2} \mathrm{O}_{2}$. The above mixture was placed onto slides for $3 \mathrm{~min}$. The slides were rinsed with PBS and fixed in ice-cold methanol. They were then dehydrated with successive solutions of ethanol-xylene (percent ethanol $=70,80,95,95,100,100 \%$ ), followed by two washes in $100 \%$ xylene (19). No attempt was made to block endogenous peroxidase activity since tissues in frozen sections tend to have much less activity than paraffin-embedded tissues. There was no increase in specific staining when a blocking step was used. In other experiments, slides were prepared and incubated with P1B3 or rotavirus antibody as above. After rinsing and soaking in cold PBS, the slides were incubated with fluorescein isothiocyanate-conjugated $\mathrm{F}\left(\mathrm{ab}^{\prime}\right)_{2}$ fragments of goat anti-mouse antibody (1:80 dilution) (Sigma Chemical Co.) for $15 \mathrm{~min}$. Slides were then rinsed in cold PBS and visualized using a fluorescence microscope.

Immunocytochemical detection of $L D L$ receptors with the polyclonal anti-LDL receptor antibody. Tissues were fixed and prepared as described by Boyles et al. (20) with slight modifications. Briefly, pentobarbital-anesthetized rats were perfused through the left ventricle of the heart with ice-cold MEM at a pressure of $100-110 \mathrm{~mm} \mathrm{Hg}$ for 5 min using a 16-gauge cannula. The right auricle was cut before the infusion of medium. The perfusion solution was then changed to icecold formaldehyde (4\%), freshly prepared from paraformaldehyde, in $0.15 \mathrm{M}$ phosphate buffer ( $\mathrm{pH}$ 7.4) and the perfusion continued for an additional $10 \mathrm{~min}$. Samples of the skeletal muscle and small (duodenum, jejunum, ileum) and large intestine were excised, as well as the adrenals and, in two experiments, the brain, and placed in ice-cold fixative. For preparation of liver sections, animals were not perfused, but sections of fresh tissue were rapidly excised and placed in the formaldehyde fixative. The tissues were cut into $0.5-\mathrm{cm}^{2}$ pieces and incubated in fixative for an additional $3 \mathrm{~h}$, after which they were rinsed twice with PBS and incubated in the refrigerator overnight in $18 \%$ sucrose in PBS. The tissues were then quick-frozen in OCT and sectioned immediately or stored under liquid nitrogen. Tissue sections ( 5 $\mu \mathrm{m})$ were collected on gelatin-coated slides and incubated with $0.1 \%$ nonfat milk, $0.15 \mathrm{M}$ ammonium acetate, $0.15 \%$ Triton $\mathrm{X}-100$, normal goat serum (diluted 1:50) in one-half strength PBS (pH 7.4) at room temperature for $1 \mathrm{~h}$ to reduce nonspecific binding of immunoglobulin. The tissues were then transferred to a solution containing $0.1 \%$ nonfat milk, $15 \mathrm{mM}$ ammonium acetate, $0.15 \%$ Triton X-100, normal goat serum (diluted 1:50) in PBS with the addition of either $1-2 \mu \mathrm{g} / \mathrm{ml}$ rabbit anti-LDL receptor polyclonal IgG or normal rabbit IgG overnight at $4^{\circ} \mathrm{C}$. The tissue sections were rinsed briefly in a wash solution consisting of $0.1 \%$ nonfat milk and $15 \mathrm{mM}$ ammonium acetate in PBS and then incubated overnight at $4^{\circ} \mathrm{C}$ in fresh wash solution followed by an additional brief rinse to remove unbound immunoglobulin. The rinsed tissue was then incubated with a diluted (1:200) preparation of goat anti-rabbit IgG $\mathrm{F}\left(\mathrm{ab}^{\prime}\right)_{2}$ fragment coupled with horseradish perox- 


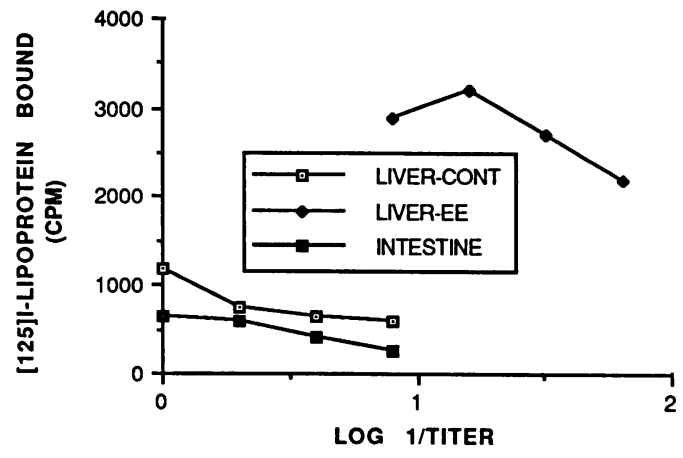

Figure 2. Detection of immunoreactive LDL receptors that bind lipoprotein in liver and intestine. Membranes were prepared from liver of normal (liver-cont) or ethinyl estradiol-treated (liver-EE) rats and intestine from normal rats as described in Methods. The plates were incubated, first with protein A, then with rabbit anti-rat LDL receptor IgG and finally, with CHAPS-solubilized membranes. To assess the number of intact LDL receptors in the membranes, ${ }^{125} \mathrm{I}$ chylomicron remnants were placed in the wells. After washing, radioactivity was determined.

idase in wash solution at room temperature for $4 \mathrm{~h}$. The tissue sections were then rinsed in wash solution and the peroxidase detected by first incubating with $0.4 \mathrm{mg} / \mathrm{ml}$ diaminobenzidine dissolved in $0.1 \mathrm{M}$ monobasic sodium phosphate (pH 6.4 with ammonium hydroxide) containing $0.06 \%$ nickel chloride for $5 \mathrm{~min}$ at room temperature followed by the addition of hydrogen peroxide $(0.03 \%)$ and incubation for $2 \mathrm{~min}$. The sections were then rinsed with PBS, dehydrated with ethanol, cleared with xylene, and mounted with Permount.

Immunoblotting of cell membranes. Cell membranes from rat liver, small intestine (jejunum and ileum), adrenal, skeletal muscle, cerebral cortex, and cerebellum were prepared by differential centrifugation and solubilized in buffer containing CHAPS as described previously (21). Samples of the solubilized membranes ( $300 \mu \mathrm{g}$ of protein, except for liver of ethinyl estradiol-treated animals where $30 \mu \mathrm{g}$ was used) were then separated on 3-8\% SDS-polyacrylamide gels according to the method of Laemmli (22) under nonreducing conditions and then transferred to nitrocellulose ( $175 \mathrm{~mA}$ for $14-18 \mathrm{~h}$ ). The immunoblotting for LDL receptor was conducted as described previously (21), except a 1:1,000 dilution of rabbit polyclonal anti-LDL receptor serum was used and the bound rabbit IgG detected by an ${ }^{125} \mathrm{I}$-labeled goat anti-rabbit IgG followed by autoradiography. Samples of nonsolubilized membranes (150 and $300 \mu \mathrm{g}$ of protein) prepared from crypt and villus cell, isolated by the method of Bjerknes and Cheng (23), were also examined, but were first separated on 5\% SDS-polyacrylamide gels before immunoblotting as described above.

Assay for active LDL receptors. Protein A $(50 \mu \mathrm{l}$ of a $75 \mu \mathrm{l} / \mathrm{ml}$ solution) was placed in the well of a microtiter plate (Dynatech Laboratories, Inc., Chantilly, VA) and incubated overnight at $4^{\circ} \mathrm{C}$. After washing three times with PBS containing $2 \%$ bovine serum albumin, $50 \mu$ of polyclonal anti-LDL receptor antibody or nonimmune rabbit IgG was added and the plate incubated for $2 \mathrm{~h}$ at room temperature. The plate was again washed and $50 \mu \mathrm{l}$ of a membrane solution in CHAPS, as described above $(5.4 \mathrm{mg} / \mathrm{ml})$, was added and incubated for $2 \mathrm{~h}$ at room temperature. After washing $50 \mu \mathrm{l}$ of ${ }^{125} \mathrm{I}$-labeled remnants (24) was added and incubated for $2 \mathrm{~h}$. After washing, the wells were cut and counted.

\section{Results}

Immunoblotting of cell membranes. To assess the presence of immunoreactive LDL receptors in the tissues to be studied and to confirm the specificity of the polyclonal anti-rat liver LDL receptor antibody (21), membranes were prepared from liver, adrenal gland, cerebral cortex, cerebellum, striated muscle, and small intestine. The membrane proteins were separated by electrophoresis on 3-8\% polyacrylamide gradient gels and transferred to nitrocellulose for immunoblotting. In liver, a number of bands were seen (Fig. 1). The same amounts of protein were loaded on the gel for all samples, except for liver from ethinyl estradiol-treated animals where one-tenth of the amount of protein was used to compensate for the marked induction of the LDL receptor. In some preparations of liver, a band of higher molecular mass $(\approx 300 \mathrm{kD})$ is present. Although this is the general region of the LDL receptor homologous protein (LRP) described by Herz et al. (25), when the LRP was visualized with an antibody to its cytosolic domain, its molecular mass $(\approx 500 \mathrm{kD})$ is definitely greater than the protein seen with the anti-LDL receptor antibody (not shown). This band was not visible in the other tissues. Our working assumption is that it is a dimer of the LDL receptor. Further, in experiments not shown here, $2 \%$ acrylamide, $0.5 \%$ agarose gels were used to insure complete entry into the gel and

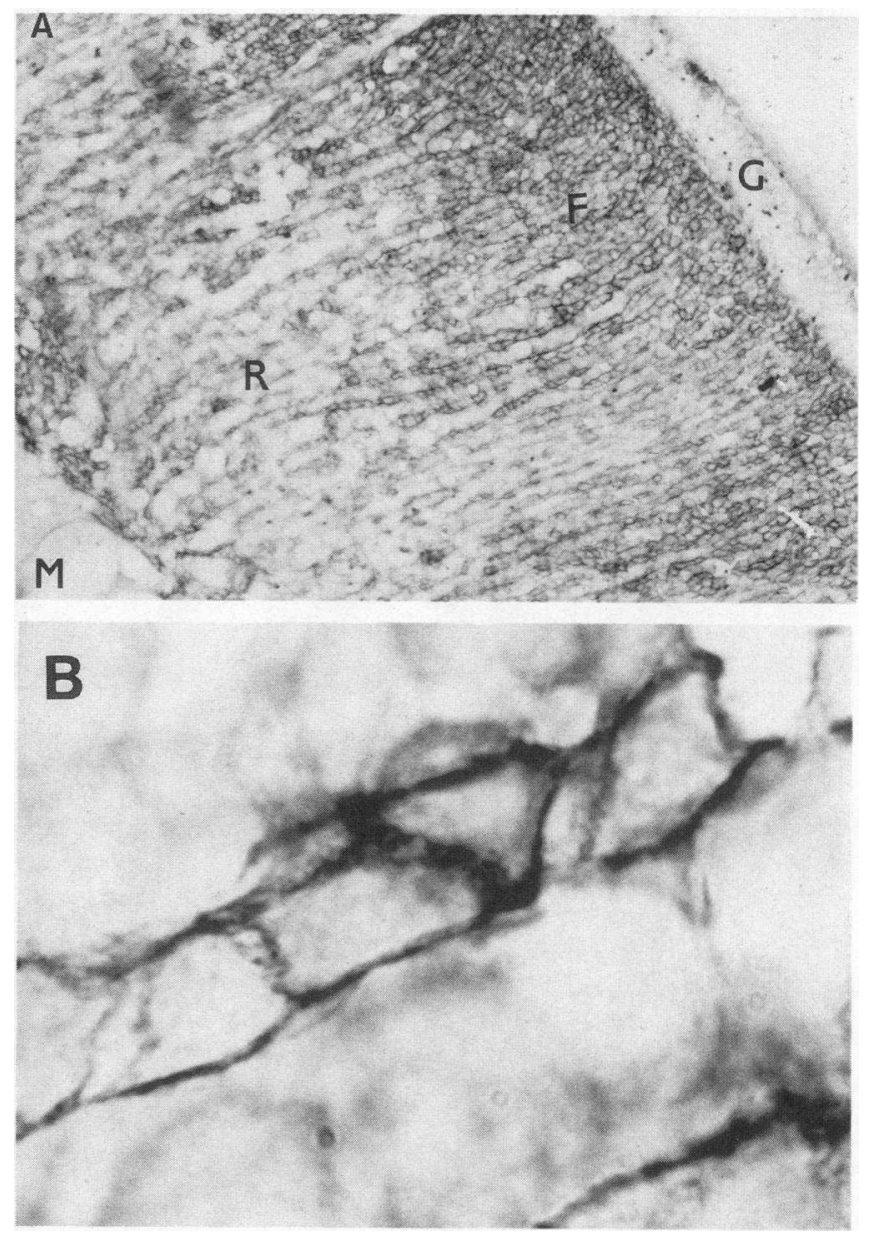

Figure 3. Immunohistology of the adrenal gland stained with antiLDL receptor antibody. Adrenal gland was perfusion-fixed and frozen in OCT. Tissue sections $(5 \mu \mathrm{m})$ were incubated, first with rabbit anti-rat $L D L$ receptor $\operatorname{IgG}$, then goat anti-rabbit $\operatorname{IgG~} \mathrm{F}\left(\mathrm{ab}^{\prime}\right)_{2}$ fragment coupled with horseradish peroxidase and finally diaminobenzidine and hydrogen peroxide. $(A)$ Low power $(\times 100), G$, zona glomerulosa; $F$, zona fasciculata; $R$, zona reticularis; M, medulla; $(B)$ High power in zona fasciculata $(\times 200)$. 
transfer of the high molecular weight protein to nitrocellulose. Again, there was no cross-reactivity seen between LDL receptor and LRP from membranes or a partially purified LRP preparation. Herz has also found a lack of cross-reactivity between this antibody and LRP in rat liver membranes (Herz, J., personal communication). Thus, it is concluded that the antiLDL receptor antibody does not react to an appreciable degree with the LRP of Herz et al. (25). In liver, a number of bands that are smaller than the LDL receptor are seen (Fig. $1 A$, lane 2). These are related to the LDL receptor since they are induced by ethinyl estradiol (Fig. $1 A$, lane 1 ) treatment and are recognized by monoclonal anti-LDL receptor antibodies (21). Thus, they are probably degradation fragments (21).

In the adrenal, a major band of the size of the LDL receptor is seen (Fig. $1 A$, lane 3 ). In striated muscle (Fig. $1 A$, lane 8 ) and in cerebral cortex (Fig. $1 A$, lane 6 ), the LDL receptor is present at a very low concentration, and the LDL receptor could be observed in cerebellar tissue as well (Fig. $1 \mathrm{~A}$, lane 7). Similarly, in intestine, only a band of the LDL receptor is seen (Fig. $1 A$, lane 4). Subsequent studies revealed that the receptor was located in both isolated crypt and villus cells (Fig. $1 B$ ) that were prepared by the method of Bjerknes and Cheng (23).
There is some variability in the precise migration of the LDL receptor in various tissues with less migration in tissues of lower receptor content. This could be due to differences in glycosylation, but is more likely a concentration effect.

The presence of immunologically reactive receptors does not always correlate with functionally active receptors since, for example, it has been reported that some intracellular asiologlycoprotein receptors do not bind ligand (26). Thus, a two stage assay was established to verify that the LDL receptors in liver and intestine are able to bind lipoprotein. Microtiter plates were coated with anti-receptor antibody, incubated with solubilized membranes, washed and then incubated with radiolabeled apoE-rich lipoprotein. Nonspecific binding (no membrane) was subtracted. Binding to solubilized intestinal membranes was definitely detectable and was about half that of liver membranes (Fig. 2). As expected, ethinyl estradiol treatment caused marked induction of binding to liver membrane.

Taken together, these results establish that the polyclonal anti-receptor antibody is quite specific and recognizes functionally capable LDL receptors present in the intestine. Thus, it should be useful for localizing these receptors in the intestine
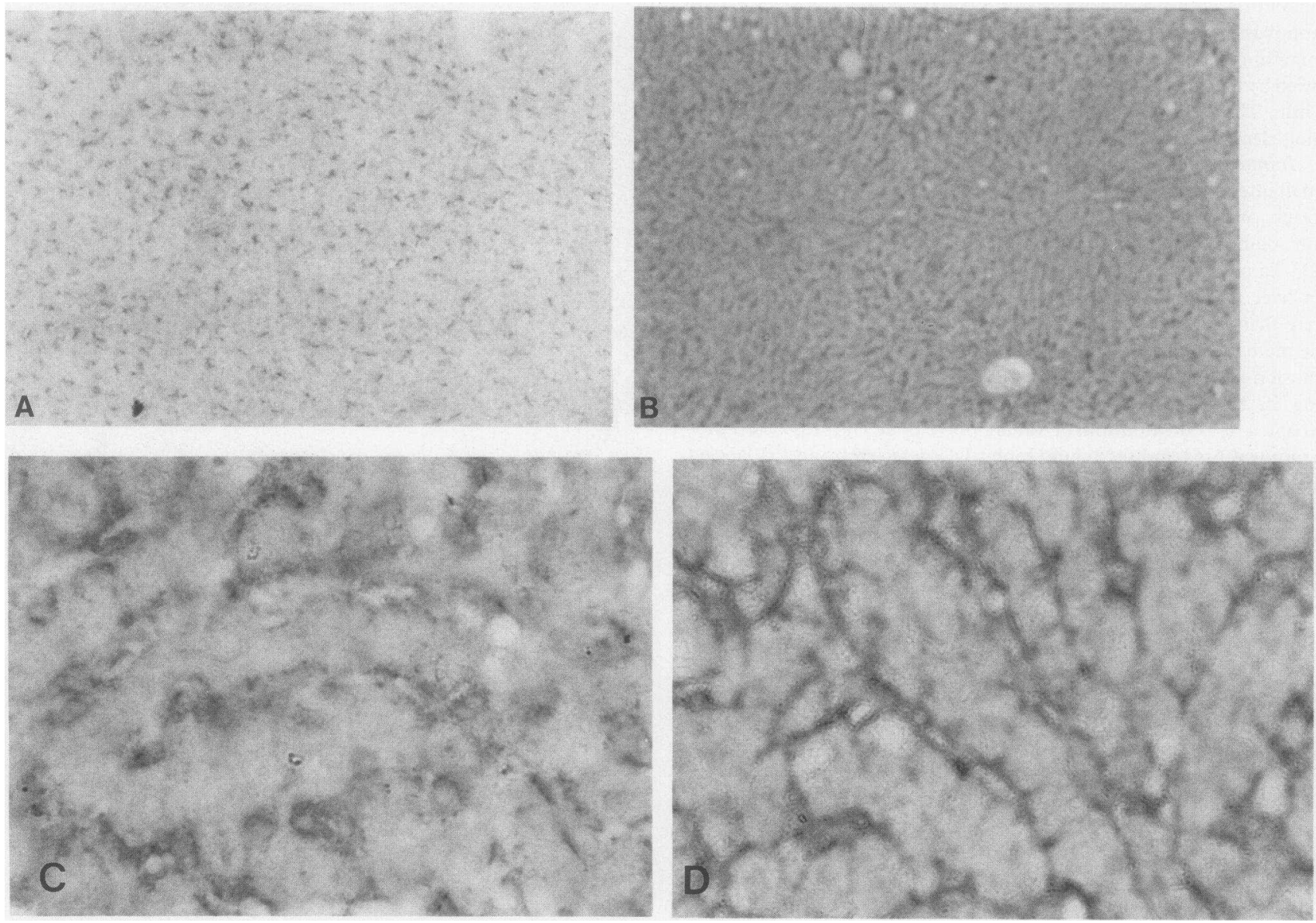

Figure 4. Immunohistology of the liver stained with anti-LDL receptor antibody. Normal rats or rats pretreated for $5 \mathrm{~d}$ with ethinyl estradiol were sacrificed and their livers removed and fixed in paraformaldehyde without pre-perfusion. Sections of the livers were stained with either nonimmune rabbit IgG (normal only, $A$ ) or rabbit anti-rat LDL receptor IgG $(B-D)$. Sections were counterstained with methyl green. $(A)$ Nonimmune IgG, low power; $(B)$ normal liver, anti-receptor antibody, low power; $(C)$ normal liver, anti-LDL receptor antibody, high power; $(D)$ liver of ethinyl estradiol-treated animal, anti-LDL receptor antibody, high power. 
as well as the adrenal gland. The brain and striated muscle should serve as controls for specificity because of their low levels of LDL receptors.

Immunohistochemistry of brain, skeletal muscle, adrenal gland, and liver. Based on studies of LDL binding and LDL accumulation conducted by others $(2,3,14)$, it was anticipated that skeletal muscle would have few, if any, detectable LDL receptors and that cerebral cortex would have a low level of receptor confined to the layer near the surface. In the sections of skeletal muscle that we examined, there was virtually no detectable LDL receptor immunoreactivity (not shown). In the cerebral cortex, there was punctate-like staining at or near the surface of the cortex (not shown). Whether this is associated with astrocytes as described by others (20) is not known.

In contrast, adrenal gland is known to be the richest source of $\operatorname{LDL}$ receptor $(2,3,5)$, and as expected, it stained intensely with the anti-LDL receptor antibody, but the staining was not uniform throughout (Fig. $3 A$ ). LDL receptors appear to be absent from the capsule and zona glomerulosa and are most dense in the zona fasciculata where the entire cell membrane is stained darkly (Fig. $3 \mathrm{~B}$ ). The intensity of staining decreases in the midzone and increases variably in the inner cortical zone (zona reticularis). There was much less specific staining in the medulla. There was no staining with nonimmune IgG by this technique (not shown).

In liver stained with nonimmune IgG, there was staining in the lumen of blood vessels (Fig. $4 \mathrm{~A}$ ), probably from peroxidases in blood elements, but little staining in parenchymal cells. With immune IgG, there was clear staining on the hepatic parenchymal cells (Fig. $4, B-D$ ). There was no discernible difference between staining in the pericentral and periportal regions. This is a contrast to what has been reported for 3-hydroxy-3-methyl glutaryl (HMG) coenzyme A reductase (27), a protein often regulated coordinately with the LDL receptor. Interestingly, the staining was primarily at the sinusoidal surfaces with very little staining in the areas of junction of the hepatocytes (Fig. $4 C$ ). Pretreatment of the rats with ethinyl estradiol caused a uniform induction of the receptor in the liver (Fig. $4 \mathrm{D}$ ). Taken together, these results help confirm the specificity of the antibody and demonstrate its utility for cellular and gross subcellular localization of LDL receptors.

$L D L$ receptor localization in the jejunum. The jejunum is the principal site of active absorption of most nutrients, including lipids and is the most active site of lipoprotein formation (28). Staining of this tissue with nonimmune IgG was confined to cells of the lamina propria which are probably leukocytes with high levels of endogenous peroxidase. There was no staining of epithelial cells (Fig. $5 \mathrm{~A}$ ). In the jejunum, the receptors, as judged by the density of immune staining, were most abundant in the cells at the base of the villus and were present, at least to the level of midvillus cells (Fig. $5 \mathrm{~B}$ ). Although staining was definitely present in crypt cells, it was always fainter than in the cells of the base to midvillus region (Fig. $5 \mathrm{~B}$ ). This finding was consistent and was observed in all of the four animals studied.

Villus cells were isolated by the method of Bjerknes and Cheng (29) and membranes prepared. Western blotting (Fig. 1 $B$ ) confirmed that LDL receptors were indeed present in these membranes.

In some particularly well-fixed preparations, the subcellular localization could be evaluated (Fig. 6). The staining was primarily in the basal lateral membrane in the crypt and lower villus cells (Fig. 6, $A$ and $B$ ). However, in cells toward the villus tip, staining in the perinuclear region could be appreciated (Fig. 6, $A$ and $C$ ).

Since the finding of LDL receptors in villus cells is contrary to what was anticipated from the report of Stange and Dietschy (10), this localization was further tested by staining with the monoclonal anti-LDL receptor antibody. This antibody has substantially lower affinity for the receptor than the polyclonal antibody and did not react with fixed tissue. It did, however, react with frozen tissue. Owing to autolysis, the histology was not well-preserved by this method. The overall distribution of staining (Fig. 7) was similar to that obtained with the polyclonal antibody, although subcellular detail was not appreciable and staining was more diffuse. This was true for development of the second antibody with either horseradish peroxidase or fluorescein (not shown) conjugated second antibodies.

Immunohistochemistry of ileum, duodenum, and colon. In no instance was there staining of epithelial cells with nonimmune IgG in ileum or duodenum (not shown). In colon, the background was diffuse and somewhat higher, probably because of trapping in mucus. In the duodenum, the distribution of anti-receptor reactivity was generally similar to that in jejunum with, perhaps somewhat more staining in the crypt area

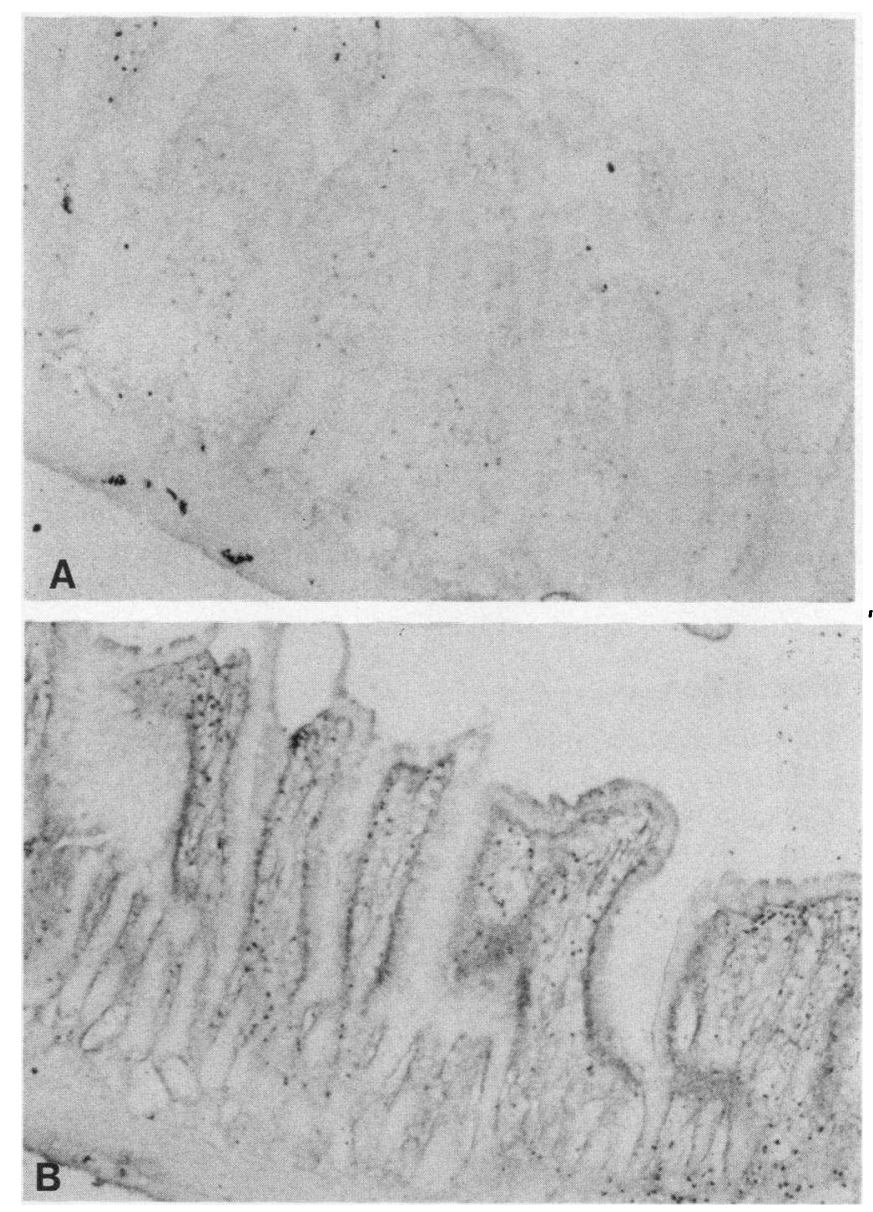

Figure 5. Immunohistology of jejunum stained with polyclonal antiLDL receptor antibody. Sections of jejunum were prepared and stained as in the legend to Fig. 3. $(A)$ Nonimmune IgG, low power; $(B)$ similar sections stained with rabbit anti-rat LDL receptor antibody, low power. 

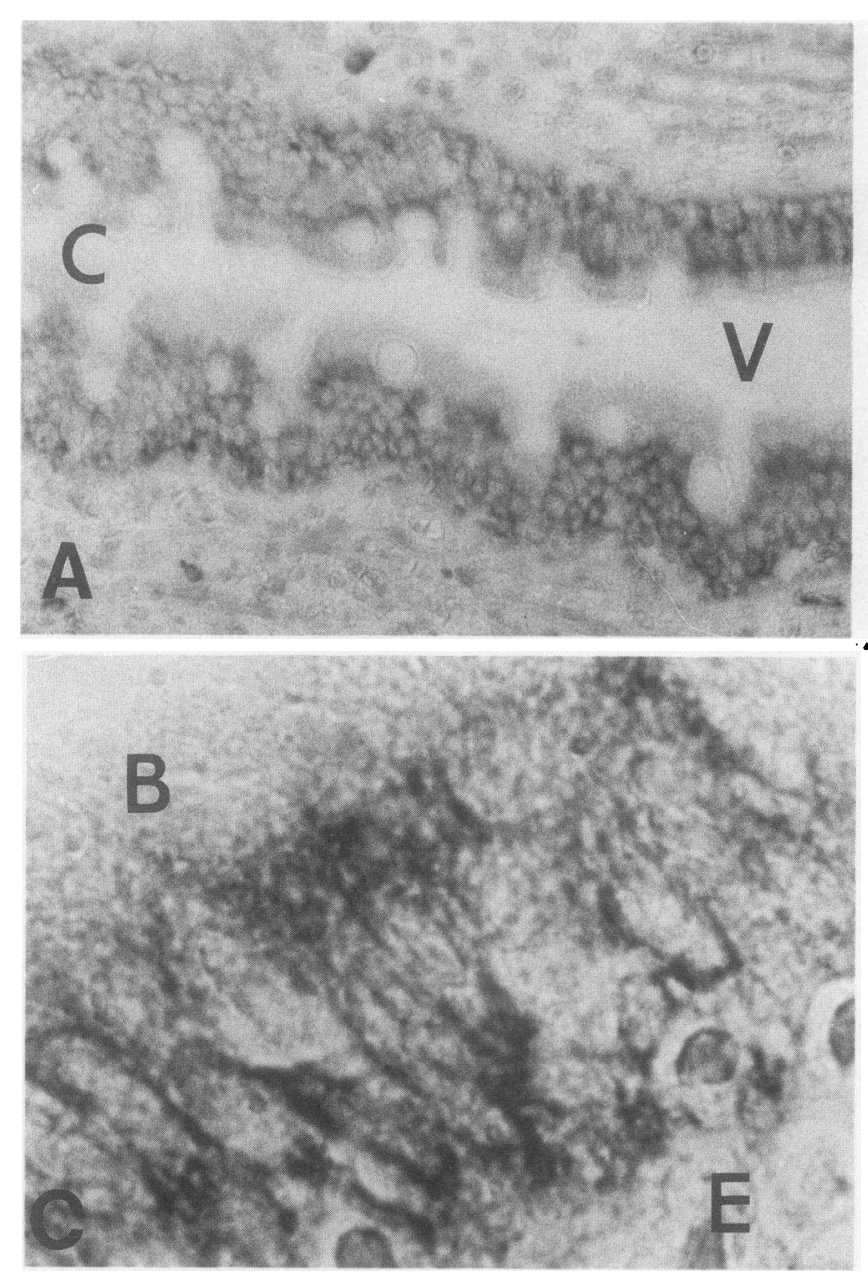

(Fig. $8 \mathrm{~A}$ ). In the ileum, staining was intense in both the crypt and the villus cells (Fig. $8 \mathrm{~B}$ ). The pattern in colon was somewhat different. Staining was uniformly intense along the basal lateral region of the epithelium at all levels (Fig. 8, $C$ and $D$ ). The distribution of receptor immunoreactivity in these tissues was the same with monoclonal antibody stains of frozen tissue as with the polyclonal antibody (not shown).

\section{Discussion}

These results, obtained with immunohistochemical staining, add to our understanding of the localization of LDL receptors. The validity of the results depends upon the specificity of the antibodies used. These reagents have been characterized and used in several other published studies from this laboratory $(21,29,30)$. The antigen used for immunization of rabbits is purified by affinity chromatography with a monoclonal antirat LDL receptor column and contains only one band on gel electrophoresis. Although Western blots of liver membranes disclose several minor binds, all of these proteins seem to be related to the LDL receptor since they are recognized by both the mono- and polyclonal antibodies and are regulated in concert by acts such as ethinyl estradiol treatment and cholesterol feeding. The band at $\approx 116 \mathrm{kD}$ appears to be the precursor of the mature LDL receptor while the band at high molecular mass may be a dimer. These have been noted by Schneider et al. (31) in the past. The remaining bands are most likely degradation fragments. There is no evidence for cross-reactivity of

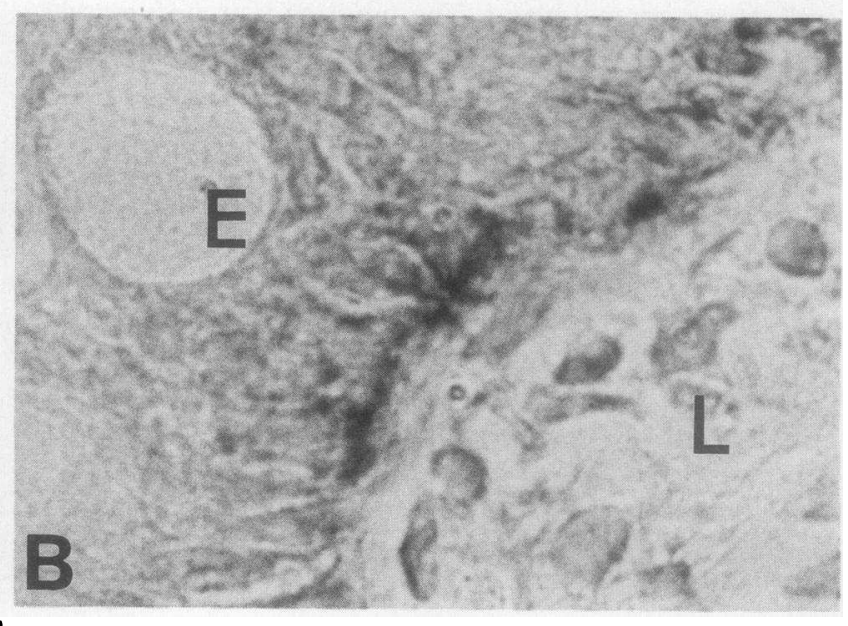

Figure 6. Subcellular localization of LDL receptors in jejunum with polyclonal anti-LDL receptor antibody. Jejunal tissue was prepared as described in the legend to Fig. 3. A well-fixed preparation of jejunum was stained with rabbit anti-rat LDL receptor and counterstained with methylene blue. $C$ and $V$ denote crypt and villus tip locations, respectively; $E$, enterocyte; $L$, lamina propria; B, brush

boarder. $(A)$ High power; $(B)$ oil immersion of the base of villus; $(C)$ oil immersion toward tip of the villus, showing area of greatest receptor density.

the polyclonal anti-LDL receptor antibody with the LRP of Herz et al. (25) despite its homology with the LDL receptor, even in liver where this protein is abundant (see Results). Thus, if there is cross-reactivity with this or other proteins, it is likely to be at such a low level that it does not contribute to observed staining. There were only small amounts of immunologically crossreacting protein on Western blots of brain and muscle, and as expected, there was little staining of these tissues on immunohistochemistry. The cross-reacting proteins in muscle may have been on trapped blood elements since monocytes and lymphocytes do have LDL receptors. Anti-LDL receptor immunoreactivity was reported in rat brain by Pitas et al. (32). It was associated with astrocytes along the pial membrane at the surface of the cerebral cortex and in fiber tracts of the cerebellum. LDL receptor mRNA seems to be similarly distributed (33). We did not examine the cerebellum; however, faint staining was present only at the surface of the cerebral cortex. Thus, these tissues serve to demonstrate the lack of non-specific crossreactivity with the anti-LDL receptor antibody.

In the adrenal gland, the zona fasciculata had the greatest density of receptors. This is consistent with its high rate of corticosterone synthesis (34). This is in contrast to the results of Nonomura et al. $(35,36)$, who suggested that $L D L$ receptors were equally abundant in inner and outer zones of the adrenal gland. However, since the "outer" zones included both glomerulosa and fasciculata, on average these cells may have a 

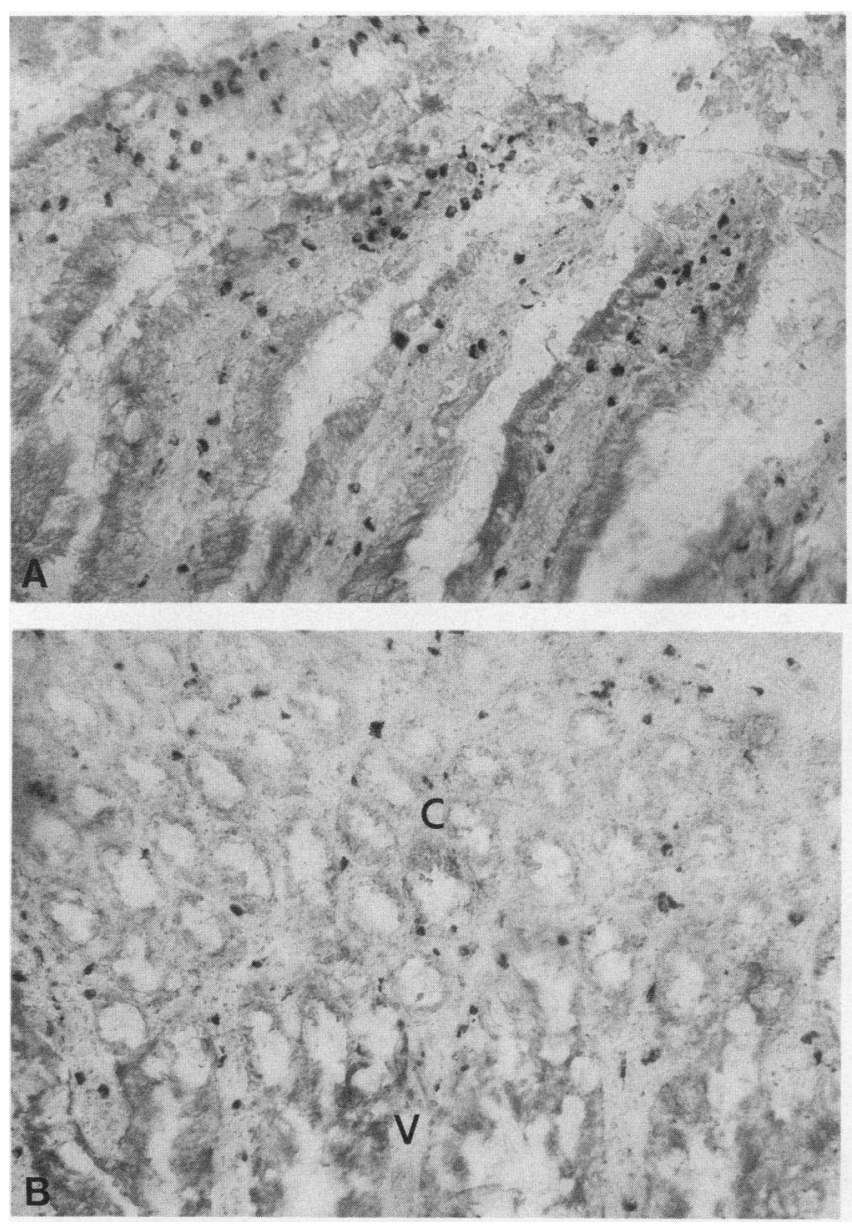

Figure 7. Immunohistology of jejunum stained with monoclonal anti-LDL receptor antibody. Jejunum was quick frozen in liquid $\mathrm{N}_{2}$ and stained with a monoclonal anti-rat LDL receptor antibody. The second antibody was horseradish peroxidase-conjugated goat antimouse IgG. High power is shown. $(A)$ Villus region; $(B)$ crypt region.

similar density to the reticularis which is also heterogeneous. The distribution of LDL receptor mRNA in adrenal gland as determined by in situ hybridization, as published by Swanson et al. (33), seemed reasonably similar to the histochemical staining in this study and is consistent with the variable rates of cholesterol utilization by cells in this organ. These results substantiate the ability of this technique to visualize relatively subtle differences in LDL receptor density at a cellular level.

Liver was expected to be rich in LDL receptors, and indeed it was. However, the general, but not absolute (37) concordance between LDL receptors and HMG CoA reductase activity might have predicted a gradient in receptor density between periportal and pericentral zones for the LDL receptor, as has been reported for the enzyme (27); however, such a gradient was not obvious. Ethinyl estradiol pretreatment increased the intensity of staining with the antibody in the liver, but did not affect its distribution within the lobule, as it does for HMG CoA reductase (27). Since LDL receptors are present even in the liver of dogs fed a very high cholesterol diet (38), there may be a constitutive expression of LDL receptor by liver cells. This concept is worthy of further exploration. The receptors were much more dense in the perisinusoidal membranes as compared to the portion of plasma membranes adjacent to other hepatocytes. This is consistent with their known localization in areas of active endocytosis (1).

The above results were consistent with what has been elucidated by other techniques regarding cellular as well as gross subcellular localization of LDL receptors and support the use of this approach to study such issues in other tissues and in altered physiologic states.

The results obtained with intestine were particularly interesting and open avenues for further research on the regulation of LDL receptor physiology in this organ. The major source of nonspecific reactivity in intestine appears to be due to inflammatory cells located in the lamina propria. Most likely, this is due to the fact that monocyte-macrophages have Fc receptors which can bind antibody nonspecifically, and that polymorphonuclear leucocytes have endogenous peroxidase activity. These cells were prominent in intestine. Thus, although such cells almost certainly have LDL receptors in vivo and their staining was darker with specific antibody, the level of their reactivity may not reflect their actual LDL receptor level since they were moderately reactive when stained with nonimmune IgG.

Although Stange et al. (10) had reported that LDL with a labeled nondegradable adduct accumulated primarily in the crypt cells, the results of this study do not support that conclusion. At all levels of the intestine, the villus cells were rich in LDL receptors; and in the jejunum, these were the primary site of immune localization of receptor. The similarity of staining patterns with both mono- and polyclonal antibodies and with two different second stages for development further suggest that the LDL receptor is being studied. Stange et al. (10) fractionated the intestinal cell types by the method of Weiser (39). It is possible that cells from the lower villus region were not released by the incubation and, thus were included in the crypt fraction. The precision of various methods of separating crypt and villus cells has been studied by Bjorkman and his colleagues (40) who concluded that the method of Bjerknes and Cheng (23) was superior to that of Weiser (39) which did not provide precise separation. We used the Bjerknes and Cheng (23) method to confirm biochemically that there are LDL receptors in villus cells.

Cells of the midvillus region, i.e., those below the tip, are the most rich in the enzymes involved in digestion (41) as well as in acyl-coenzyme A cholesterol acyltransferase (42), the cholesterol-esterifying enzyme that may play a role in cholesterol absorption and are very active in lipoprotein formation (43). It is further worthwhile noting that lipoprotein formation proceeds whether there is exogenous lipid or not (44), and the synthesis of apoB continues, although at a somewhat reduced rate, even after bile diversion (45). The presence of receptors in villus cells raises the interesting possibility that endogenous cholesterol from LDL contributes, along with exogenous cholesterol and newly synthesized sterol, to the formation of lipoproteins. Such a pathway could be subject to regulation and, if specifically enhanced, enterohepatic recycling of LDL could provide a route for increasing LDL catabolism with more efficient cholesterol utilization. The presence of LDL receptors in crypts at a relatively uniform level throughout the intestine is certainly consistent with a role of endogenous cholesterol in the rapid cell growth and division that occurs in the cells at this level of the intestine. It is interesting to speculate that changes in differentiation or growth states in intestine will cause changes in receptor density in these cells. 

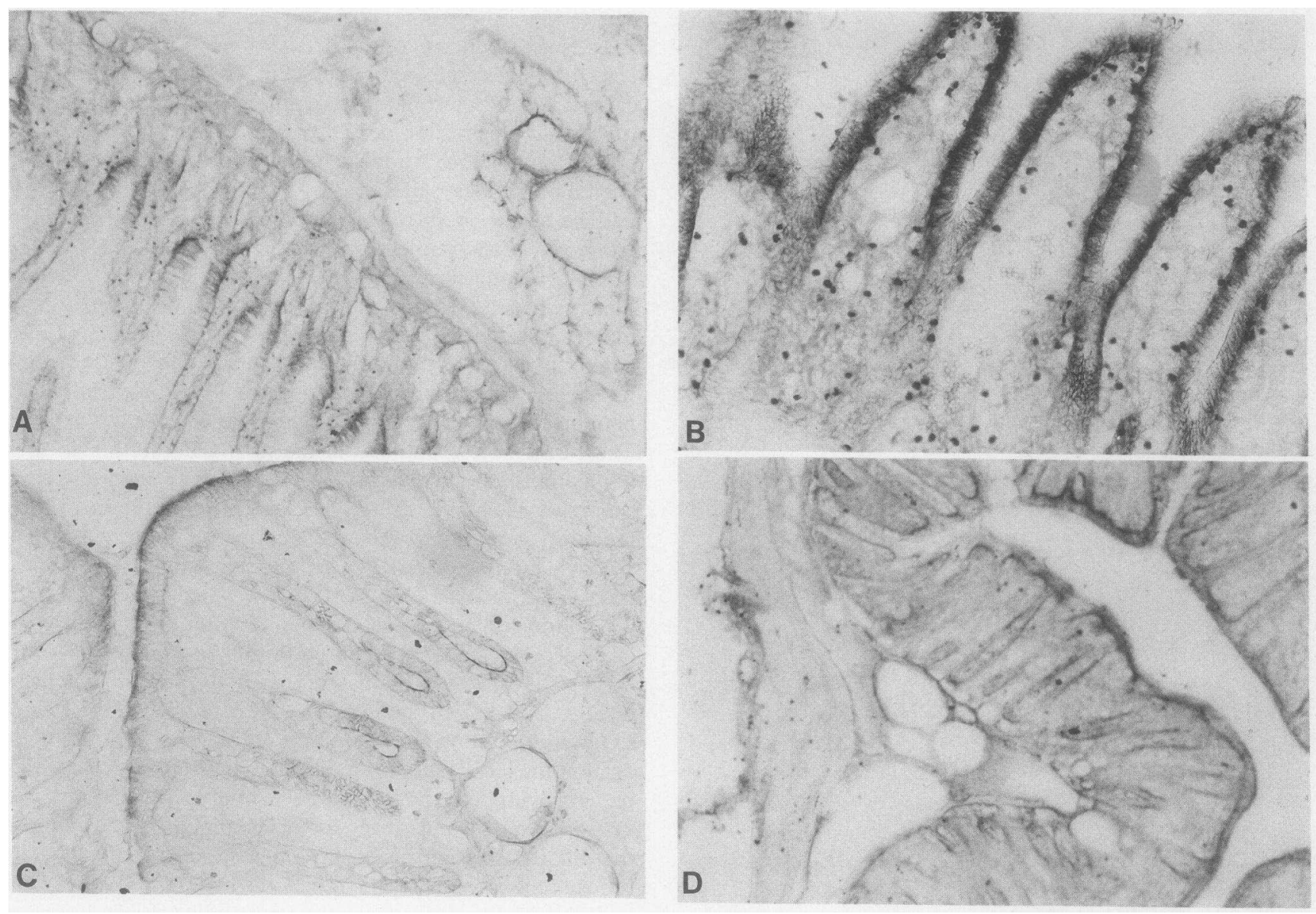

Figure 8. Immunohistology of ileum, duodenum, and colon stained with polyclonal anti-LDL receptor antibody. $(A)$ Duodenum, low power; $(B)$ ileum, low power; $(C)$ colon, low power; $(D)$ colon, high power.

The subcellular distribution of the LDL receptor which could be visualized in some preparations was also noteworthy. As expected, most LDL receptors were located in the basal lateral membranes where they would be in contact with the plasma. However, it appears that in villus cells near the lumen, there was staining around the nucleus and around the brush boarder. This raises the interesting possibility that under some circumstances, there is a significant intracellular pool of receptors. Such a pool has been observed by us in several lines of cultured cells (Cooper et al., manuscript submitted for publication) as well as in freshly isolated adipocytes (46). The pool is regulated by insulin in the latter cells, and whether a redistribution can be induced in intestine will be determined biochemically.

The uniform intense staining in the colon is consistent with the high rate of turnover of the cells. Whether this distribution changes when these cells undergo malignant degeneration will be worth exploring. Further, the colon actively secretes mucus, and LDL receptor-derived cholesterol has been postulated to have a role in sebaceous secretion in skin (47).

Overall, the studies in this report provide new information regarding the distribution of LDL receptors within several tissues that are active in cholesterol metabolism: adrenal gland, liver and intestine. This should form the basis for future experiments on the regulation of these receptors, particularly in the intestine where a role for direct dietary regulation of LDL catabolism by this organ now seems possible.

\section{Acknowledgments}

We thank Dr. Eve Reaven for helpful discussions, Dr. Janet Boyles of the Gladstone Foundation, San Francisco for assisting us in learning the technique of tissue fixation, Ms. Martha Losch, Mr. Dan Brown, and Mr. David Gridley for assistance with some of the experiments, Dr. David Lewinsohn and the rest of the workers in the laboratories of Drs. Butcher and Rouse at the Palo Alto VA Hospital for helpful advice, Mrs. Jean Chen for preparing antibodies, and Ms. Jeanne Gill for preparing the manuscript.

This work was supported in part by National Institutes of Health grants DK-38318 and DK-36659.

\section{References}

1. Goldstein, J. L., M. S. Brown, R. G. W. Anderson, D. W. Russell, and W. J. Schneider. 1985. Receptor-mediated endocytosis: concepts emerging from the LDL receptor system. Annu. Rev. Cell Biol. 1:1-39.

2. Pittman, R. C., A. D. Attie, T. E. Carew, and D. Steinberg. 1979. Tissue sites of degradation of low density lipoprotein: application of a method for determining the fate of plasma proteins. Proc. Natl. Acad. Sci. USA. 76:534-539. 
3. Spady, D. K., D. W. Bilheimer, and J. M. Dietschy. 1983. Rates of receptor-dependent and -independent low density lipoprotein uptake in the hamster. Proc. Natl. Acad. Sci. USA. 80:3499-3503.

4. Brown, M. S., P. T. Kovanen, and J. L. Goldstein. 1981. Regulation of plasma cholesterol by lipoprotein receptors. Science (Wash. DC). 212:628-635.

5. Kovanen, P. T., S. K. Basu, J. L. Goldstein, and M. S. Brown. 1979. Low density lipoprotein receptors in bovine adrenal cortex. II. Low density lipoprotein binding to membranes prepared from fresh tissue. Endocrinology. 104:610-616.

6. Azhar, S., A. Cooper, L. Tsai, W. Maffe, and E. Reaven. 1988. Characterization of apoB, E receptor function in the luteinized ovary. J. Lipid Res. 29:869-882.

7. Andersen, J. M., and J. M. Dietschy. 1976. Cholesterogenesis: Derepression in extrahepatic tissues with 4-aminopyrazolo[3,4-d]pyrimidine. Science (Wash. DC). 193:903-905.

8. Andersen, J. M., and J. M. Dietschy. 1977. Regulation of sterol synthesis in 15 tissues of rat. II. Role of rat and human high and low density plasma lipoproteins and of rat chylomicron remnants. J. Biol. Chem. 252:3652-3659.

9. Suzuki, N., N. Fidge, P. Nestel, and J. Yin. 1983. Interaction of serum lipoproteins with the intestine: evidence for specific high density lipoprotein-binding sites on isolated rat intestinal mucosal cells. $J$. Lipid Res. 24:253-264.

10. Stange, E. F., and J. M. Dietschy. 1983. Cholesterol synthesis and low density lipoprotein uptake are regulated independently in rat small intestinal epithelium. Proc. Natl. Acad. Sci. USA. 80:5739-5743.

11. Gebhard, R. L., and A. D. Cooper. 1978. Regulation of cholesterol synthesis in cultured canine intestinal mucosa. J. Biol. Chem. 253:2790-2796.

12. Stange, E. F., M. Alavi, A. Schneider, G. Preclik, and H. Ditschuneit. 1980. Lipoprotein regulation of 3-hydroxy-3-methylglutaryl coenzyme $\mathrm{A}$ reductase in cultured intestinal mucosa. Biochim. Biophys. Acta. 620:520-527.

13. Gebhard, R. L., and W. F. Prigge. 1981. In vivo regulation of canine intestinal 3-hydroxy-3-methylglutaryl coenzyme A reductase by cholesterol, lipoprotein and fatty acid. J. Lipid Res. 22:1111-1118.

14. Yamamoto, T., R. W. Bishop, M. S. Brown, J. L. Goldstein, and D. W. Russell. 1986. Deletion in cysteine-rich region of LDL receptor impedes transport to cell surface in WHHL rabbit. Science (Wash. DC). 232:1230-1237.

15. Lipkin, M., P. Sherlock, and B. Bell. 1963. Cell renewal in stomach, ileum, colon and rectum. Gastroenterology. 45:721-729.

16. Dietschy, J. M., and M. D. Siperstein. 1965. Cholesterol synthesis by the gastrointestinal tract: localization and mechanisms of control. J. Clin. Invest. 44:1311-1327.

17. Muroya, H., H. S. Sodhi, and R. G. Gould. 1977. Sterol synthesis in intestinal villi and crypt cells of rats and guinea pigs. J. Lipid Res. 18:301-308

18. Merchant, J. L., and R. A. Heller. 1977. 3-Hydroxy-3-methylglutaryl coenzyme A reductase in isolated villous and crypt cells of the rat ileum. J. Lipid Res. 18:722-733.

19. Rouse, R. V., and R. A. Warnke. 1986. Special applications of tissue section immunologic staining in the characterization of monoclonal antibodies and in the study of normal and neoplastic tissues. In Handbook of Experimental Immunology. 4th edition. D. M. Weir, editor. C. V. Mosby Co., St. Louis, MO. 116.1-116.10.

20. Boyles, J. K., R. E. Pitas, E. Wilson, R. W. Mahley, and J. M. Taylor. 1985. Apolipoprotein $\mathrm{E}$ associated with astrocytic glia of the central nervous system and with non-myelinating glia of the peripheral nervous system. J. Clin. Invest. 76:1501-1513.

21. Cooper, A. D., R. Nutik, and J. Chen. 1987. Characterization of the estrogen-induced lipoprotein receptor in rat liver. J. Lipid Res. 28:59-68.
22. Laemmli, U. K. 1970. Cleavage of structural proteins during the assembly of the head of bacteriophage T4. Nature (Lond.). 227:680-685.

23. Bjerknes, M., and H. Cheng. 1981. Methods for the isolation of intact epithelium from the mouse intestine. Anat. Rec. 199:565-574.

24. Kris-Etherton, P. M., and A. D. Cooper. 1980. Studies on the etiology of the hyperlipemia in rats fed an atherogenic diet. J. Lipid Res. 21:435-442.

25. Herz, J., U. Hamann, S. Rogne, O. Myklebost, H. Gausepohl, and K. K. Stanley. 1988. Surface location and high affinity for calcium of a $500 \mathrm{kDa}$ liver membrane protein closely related to the LDL-receptor suggest a physiological role as lipoprotein receptor. EMBO (Eur. Mol. Biol. Organ.) J. 7:4119-4128.

26. Weigel, P. H., and J. A. Oka. 1983. The surface content of asialoglycoprotein receptors on isolated hepatocytes is reversibly modulated by changes in temperature. J. Biol. Chem. 258:5089-5094.

27. Li, A. C., R. D. Tanaka, K. Callaway, A. M. Fogelman, and P. A. Edwards. 1988. Localization of 3-hydroxy-3-methylglutaryl CoA reductase and 3-hydroxy-3-methylglutaryl $\mathrm{CoA}$ synthase in the rat liver and intestine is affected by cholestyramine and mevinolin. $J$. Lipid Res. 29:781-796.

28. Bisgaier, C. L., and R. M. Glickman. 1983. Intestinal synthesis, secretion and transport of lipoproteins. Annu. Rev. Physiol. 45:625636.

29. Ellsworth, J. L., F. B. Kraemer, and A. D. Cooper. 1987. Transport of $\beta$-VLDL and chylomicron remnants by macrophages is mediated by the low density lipoprotein receptor. J. Biol. Chem. 262:2316-2325.

30. Nagata, Y., J. Chen, and A. D. Cooper. 1988. Role of LDL receptor-dependent and -independent sites in binding and uptake of chylomicron remnants in rat liver. J. Biol. Chem. 263:15151-15158.

31. Schneider, W. J., U. Beisiegel, J. L. Goldstein, and M. S. Brown. 1982. Purification of the low density lipoprotein receptor, an acidic glycoprotein of 164,000 molecular weight. J. Biol. Chem. 257:2664-2673.

32. Pitas, R. E., J. K. Boyles, J. H. Lee, D. Hui, and K. H. Weisgraber. 1987. Lipoproteins and their receptors in the central nervous system. J. Biol. Chem. 262:14352-14360.

33. Swanson, L. W., D. M. Simmons, S. L. Hofmann, J. L. Goldstein, and M. S. Brown. 1988. Localization of mRNA for low density lipoprotein receptor and a cholesterol synthetic enzyme in rabbit nervous system by in situ hybridization. Proc. Natl. Acad. Sci. USA. 85:9821-9825.

34. Tait, J. F., S. A. S. Tait, and J. B. G. Bell. 1980. Steroid hormone production by mammalian adrenocortical dispersed cells. In Essays in Biochemistry. Volume 16. P. N. Campbell, and R. C. Marshal, editors. Academic Press, Inc., New York. 99-174.

35. Nonomura, K., T. Obara, and C. A. Strott. 1986. Low density lipoprotein receptor activity in the guinea pig adrenal cortex. I. Zonal characterization and response to adrenocorticotropin. Endocrinology. 118:653-660.

36. Nonomura, K., and C. A. Strott. 1986. Low-density lipoprotein receptor activity in the guinea pig adrenal cortex. II. Zonal response to aminoglutethimide and 17 alpha-ethinyl estradiol. Biochim. Biophys. Acta. 876:264-270.

37. Spady, D. K., S. D. Turley, and J. M. Dietschy. 1983. Dissociation of hepatic cholesterol synthesis from hepatic low-density lipoprotein uptake and biliary cholesterol saturation in female and male hamsters of different ages. Biochim. Biophys. Acta. 753:381-392.

38. Cahill, P. D., G. E. Sarris, A. D. Cooper, P. D. Wood, J. C. Kosek, R. S. Mitchell, and D. C. Miller. 1988. Inhibition of vein graft intimal thickening by eicosapentanoic acid: reduced thromboxane production without change in lipoprotein levels or low-density lipoprotein receptor density. J. Vasc. Surg. 7:108-118. 
39. Weiser, M. M. 1973. Intestinal epithelial cell surface membrane glycoprotein synthesis. J. Biol. Chem. 248:2536-2541.

40. Bjorkman, D. J., C. H. Allan, S. J. Hagen, and J. S. Trier. 1986. Structural features of absorptive cell and microvillus membrane preparations from rat small intestine. Gastroenterology. 91:1401-1414.

41. Trier, J. S., and J. L. Madara. 1981. Functional morphology of the mucosa of the small intestine. In Physiology of the Gastrointestinal Tract. Volume 2. L. R. Johnson, J. Christensen, M. I. Grossman, E. D. Jacobson, and S. G. Schultz, editors. Raven Press, New York. 925-961.

42. Field, F. J., A. D. Cooper, and S. K. Erickson. 1982. Regulation of rabbit intestinal acyl co-enzyme A-cholesterol acyltransferase in vivo and in vitro. Gastroenterology. 83:873-880.

43. Green, P. H., J. H. Lefkowitch, R. M. Glickman, J. W. Riley, E.
Quinet, and C. B. Blum. 1982. Apolipoprotein localization and quantitation in the human intestine. Gastroenterology. 83:1223-1230.

44. Jones, A. L., N. B. Ruderman, and M. G. Herrera. 1967. Electron microscopic and biochemicàl study of lipoprotein synthesis in the isolated perfused rat liver. J. Lipid Res. 8:429-446.

45. Davidson, N. O., M. E. Kollmer, and R. M. Glickman. 1986. Apolipoprotein $\mathrm{B}$ synthesis in rat small intestine: regulation by dietary triglyceride and biliary lipid. J. Lipid Res. 27:30-39.

46. Sather, S. D., K. A. May, A. D. Cooper, S. W. Cushman, and F. B. Kraemer. 1988. Distribution of LDL receptor in the isolated adipocyte. Clin. Res. 36:1159. (Abstr.)

47. Grubauer, G., K. R. Feingold, and P. M. Elias. 1987. Relationship of epidermal lipogenesis to cutaneous barrier function. J. Lipid Res. 28:746-7522. 